\title{
ENSINO, PSICOLOGIA, SAÚDE: UMA TRÍADE CONSTITUÍDA DE PRÁTICAS, QUESTÕES E POSSIBILIDADES
}

\author{
Sylvia Helena Souza da Silva Batista
}

\begin{abstract}
RESUMO
Este texto tem como objetivo desencadear discussões, análises e proposições no âmbito do Ensino da Psicologia na área da saúde. Parte de um problematização do ensino em saúde no momento contemporâneo das políticas públicas de educação e saúde no Brasil, situando como um desafio no processo de transformação dos cursos superiores na área da saúde a incorporação da concepção ampliada de saúde e a ênfase na integralidade e no cuidado no processo de formação profissional, bem como a aprendizagem para o trabalho em equipe multiprofissional e a discussão sobre os condicionantes trazidos pelos planos e projetos educacionais e assistenciais. Neste contexto, interroga para quê e para quem um Ensino de Psicologia que possa articular o cuidado, a integralidade, o controle social, a humanização e a ética, sem secundarizar as abordagens e enfoques psicológicos. Os sentidos e os sujeitos do ensino da Psicologia em saúde estão sendo decifrados e recriados, exigindo uma análise cuidadosa dos contornos político-sociais e dos projetos éticos que queremos estabelecer nas propostas de formação profissional em saúde.
\end{abstract}

\section{PALAVRAS-CHAVE}

Psicologia; Ensino; Saúde

\section{TEACHING, PSYCHOLOGY, HEALTH: A TRIAD MADE UP OF PRACTICES, ISSUES AND POSSIBILITIES}

\begin{abstract}
This text aims at bringing about discussions, analyses and propositions regarding the teaching of Psychology in the medical field. It starts presenting some problems in teaching in the medical schools at the present time in the public policies of education and health in Brazil, a main challenge being the process of transformation of the graduation courses in the medical field into the incorporation of the broadened concept of health, and the emphasis on the integrity and care in the process of professional training, as well as learning how to work within a multi-professional team, and the discussion of the conditions brought by the educational and assistance plans and projects.In this context, the question is asked what for and to whom the teaching of Psychology is directed which is able to articulate this care, integrity, social control, humanization and ethics, without putting into second place the psychological approach. The senses and subjects of the teaching of Psychology in the health area are being decoded and recreated, thus demanding a careful analysis of the social-political surroundings, and the ethical projects we want to establish within the proposals of education for health professionals.
\end{abstract}

KEYWORDS

Psychology; Teaching; Health

(C) ETD - Educação Temática Digital, Campinas, v.8, n.2, p.249-257, jun. 2007 - ISSN:1676-2592 249 


\section{DOSSIÊ \\ Área Temática: Ensino de Psicologia \\ "Diálogos sobre a Docência em Psicologia"}

No mistério do Sem Fim, equilibra-se um planeta.

E, no planeta, um jardim,

e, no jardim, um canteiro, no canteiro, uma violeta, e, sobre ela, o dia inteiro, entre o planeta e o Sem Fim, a asa de uma borboleta. (Cecília Meireles - Canção)

O Ensino da Psicologia em Cursos da Área da saúde é um tema que assume um sentido nuclear no contexto contemporâneo das políticas públicas da Educação Superior (com particular ênfase às Diretrizes Curriculares Nacionais para os Cursos de Graduação) e das políticas no campo da saúde (destacando-se assumir o Sistema Único de Saúde como o orientador da formação profissional): os cruzamentos e as possibilidades de troca no contexto do binômio saúde e educação, sinalizam questões e desafios no diálogo entre o que é considerado específico de uma área e suas contribuições para a formação de profissionais que tenham práticas coaduandas com as demandas e necessidades sociais.

Ao delinear o contexto da abordagem que será empreendida, vale situar que falo do lugar de uma professora de Psicologia da Educação que traz em sua bagagem a graduação em Psicologia e um encontro bastante significativo com as intersecções saúde e educação. Realço minha atual inserção na Universidade Federal de São Paulo - Campus Baixada Santista, onde desenvolvo minha docência junto a cinco cursos: Educação Física, Fisioterapia, Nutrição, Psicologia e Terapia Ocupacional. Nesta minha experiência, saio da métrica disciplinar e componho o grupo de professores que atuam no Eixo O Ser Humano e sua Inserção Social, articulando saberes da Antropologia, ciências sociais, Psicologia, Educação, Filosofia, Epistemologia.

Desta forma, este meu "presente" lugar traz, em si, características, possibilidades de interpretação e apropriação. Acredito nas interações sociais como espaços para que outros olhares sejam forjados e novos patamares de compreensão possam ser configurados. Eis um dos desejos deste texto. 


\title{
DOSSIÊ \\ Área Temática: Ensino de Psicologia \\ "Diálogos sobre a Docência em Psicologia"
}

\section{ENSINO EM SAÚDE: REFLEXÕES DE UMA PROFESSORA}

Focalizar o ensino em saúde como prática social, buscando novas atitudes perante o conhecimento, permite identificar uma consonância com os pressupostos que têm orientado não somente a reordenação dos serviços de saúde, mas também as políticas dos profissionais da saúde. Sobre este aspecto Feuerwerker (2003) afirma:

\begin{abstract}
Há necessidade de redefinir referenciais e relações com diferentes segmentos da sociedade no sentido da universidade construir um novo lugar social, mais relevante e comprometido com a superação das desigualdades. No campo da Saúde, é indispensável que a produção de conhecimento, formação profissional e prestação de serviços sejam tomados como indissociáveis de uma nova prática (FEUERWERKER, 2003, p.25).
\end{abstract}

Assim, a nova postura frente ao conhecimento passa, necessariamente, pelo esforço de criar espaços formativos na universidade que tragam o diálogo educação-saúde e cidadania como eixo fundante, superando o enfoque na doença para a ênfase no processo saúde-doença e tendo na transformação do modelo de atenção, na integralidade do cuidado, caminhos para contribuir para a autonomia dos sujeitos na promoção da saúde. (FEUERWERKER, 2003; CECCIN, 2005).

Batista e colaboradores (2005), Feuerwerker (2003), Almeida (2004) têm discutido como áreas de dificuldades para o ensino em saúde: as dicotomias (teoria e prática; saúde e doença; promoção e cura) na formação de novos profissionais; o biologicismo e o hospitalocentrismo na formação em saúde, reduzindo as práticas aos seus aparatos técnicos e tecnológicos; as dimensões ética e humanista consideradas em segundo plano; a formação docente frente às mudanças políticas e educacionais, incluindo uma significativa fragilidade no processo de profissionalização docente; a desvinculação dos currículos em relação às necessidades da comunidade e o distanciamento entre os cenários de aprendizagem e assistência.

Um importante desafio no processo de transformação dos cursos superiores na área da saúde refere-se à incorporação da concepção ampliada de saúde e a ênfase na integralidade e no cuidado no processo de formação profissional, bem como a aprendizagem para o trabalho em equipe multiprofissional e a discussão sobre os condicionantes trazidos pelos planos e projetos educacionais e assistenciais. Nessa direção, 
resgata-se a dimensão política da saúde, explicitada na $8^{a}$ Conferência Nacional de Saúde, em 1986: “saúde como resultante das condições de alimentação, habitação, educação, renda, meio ambiente, trabalho, transporte, emprego, lazer, liberdade, acesso e posse da terra e acesso a serviços de saúde”.

Esta concepção ampliada é reafirmada no texto da Constituição da República Federativa do Brasil, promulgada em 1988. A Lei nº 8.080, de 19 de setembro de 1990, onde é tratada a implantação do Sistema Único de Saúde, afirma que “os níveis de saúde da população expressam a organização social e econômica do País”. Agregando à dimensão política, Canguilhen (1995) situa um plano epistemológico à concepção de saúde: “a saúde é uma maneira de abordar a existência com uma sensação não apenas de possuidor ou portador, mas também, se necessário, de criador de valor, de instaurador de normas vitais” (p.163).

No contexto desta concepção ampliada, têm sido produzidas propostas de formação que buscam, em diferentes níveis, articular ensino-serviços-comunidade, formação-controle social, ensino-realidade, ensino-pesquisa-extensão. Estas propostas trazem em seus bojos expectativas de gerar impactos no modo de concretizar as propostas formativas em saúde, alterando as “rotas” do ensino e da aprendizagem tradicionais centradas nos conteúdos biológicos e na intervenção curativa, trazendo à tona a discussão do aprender como um processo que integra cognição-afeto-cultura, possibilitando o desenvolvimento de uma competência profissional vinculada a uma prática de integralidade na assistência ao indivíduo e à comunidade.

Há, assim, um reconhecimento do esgotamento dos modelos mais conhecidos de formação, indicando-se que demandas, até então neglicenciadas e/ou desvalorizadas, estão a exigir a reconfiguração dos itinerários de formação profissional em saúde, articulando, além da sempre presente tríade ensino-pesquisa e extensão, os espaços de ensino com o âmbito dos serviços e dos condicionantes criados pelas políticas públicas de saúde e educação.

Komatsu (2003), Almeida (1999), Conrado e colaboradores (2004) e Delarroza e Vannuchi (2005), no cenário nacional, relatam e analisam experiências desenvolvidas no ensino em saúde, nos cursos de Medicina, Odontologia, Enfermagem, sinalizando os 
currículos baseados na problematização e na aprendizagem baseada em problemas como potenciais espaços para o desenvolvimento e instauração de uma cultura interdisciplinar na formação universitária.

Batista e colaboradores (2005) afirmam que o enfoque problematizador traz, em suas características, a interdisciplinaridade como um eixo fundamental das situações de aprendizagem, favorecendo a troca, a construção do conhecimento, a autoria na apropriação de saberes científicos, éticos, políticos. Os autores destacam ainda, que aprender com pessoas de diferentes áreas de conhecimento parece ser uma experiência que amplia a compreensão do trabalho coletivo e da complexidade da realidade que se apresenta nos cenários em saúde.

McNair (2005) pontua com particular ênfase que para fazer junto no cotidiano do cuidado em saúde é preciso aprender junto sobre o trabalho em saúde. O autor indica que a construção da identidade profissional vai se fortalecendo a medida que os estudantes são expostos a situações comuns de aprendizagem, pois a complexidade da prática explicita a demanda por olhares diferentes, que ora se complementam, ora se confrontam, mas que possibilitam um nível mais ampliado de compreensão da realidade.

Nesse sentido, propostas curriculares que sinalizam novos lugares para professor, aluno e conhecimento, apontando para relações de proximidade e troca com o cotidiano dos serviços, em uma perspectiva do trabalho em saúde como algo que transcende os fazeres individualizados de cada profissão, têm sido assumidas como potencialmente importantes para a construção de caminhos formativos que lidem com as ciências como elaborações humanas historicamente condicionadas. Projeta-se um profissional de saúde que, não abrindo mão ou banalizando a formação científica, possa estar atento às diferenças, aos movimentos de inclusão, ao humano e social presente em todas as suas ações.

\section{O ENSINO DA PSICOLOGIA: PARA QUÊ? PARA QUEM?}

O percurso construído nos lança ao desafio da construção de propostas de ensino de Psicologia em saúde que possa articular o cuidado, a integralidade, o controle social, a humanização e a ética, sem secundarizar as abordagens e enfoques psicológicos. A dialética entre conhecer e fazer delineia um contexto em que a formação: 
(...) traz em si uma intencionalidade que opera tanto nas dimensões subjetivas (caráter, mentalidade) como nas dimensões intersubjetivas, aí incluídos os desdobramentos quanto ao trajeto de constituição no mundo de trabalho (conhecimento profissional). Portanto, não se trata de algo relativo a apenas uma etapa ou fase do desenvolvimento humano, mas sim como algo que percorre, atravessa e constitui a história dos homens como seres sociais, políticos e culturais (BATISTA, 2001, p.134).

Formação, a partir desse entendimento, envolve, dentre outros, planos epistemológico e prático (experiencial) de aprendizagem. No plano epistemológico, identifica-se que aprender articula cognição, afeto e cultura em uma perspectiva históricosocial, trazendo a questão da mediação e da intersubjetividade. Mediar a aprendizagem do cuidado implica sair da ênfase na doença, da abordagem biologicista das condições de vida e das relações de causalidade linear entre sujeito e objeto. Sair desse espectro possibilita dimensionar uma formação em saúde que se funde nas condições concretas de vida.

No plano prático (experiencial), a aprendizagem vincula-se à prática e ao cotidiano, evidenciando que aprender e fazer apresentam dinâmicas de conexão, complementariedade e atribuição de significados. Nesse âmbito, emerge a formação como projeto: possibilidade de construir novos sentidos para a formação em saúde, respondendo aos desafios contemporâneos da ética, da integralidade, do cuidado e da intersetorialidade.

Nesse projeto de formação, a Psicologia como ciência e profissão tem um lugar importante.

Um lugar que me parece atravessado pela perspectiva interdisciplinar, exigindo uma rigorosa revisão e ruptura com as formas tradicionais de se entender e produzir conhecimento científico, procurando (des)revelar territórios rigidamente delimitados e construir ilhas de racionalidade: representações construídas intersubjetivamente em função das necessidades da situação, considerando o contexto, os sujeitos envolvidos, as interlocuções privilegiadas, os objetivos delineados, os resultados esperados (Fourez,2001).

Desenha-se um traço de movimento provisório na interdisciplinaridade que exige o reconhecimento de que as verdades científicas são produções relativas a um espaço, a um tempo e portanto, são elaboradas, partilhadas, aceitas, contestadas, superadas, revisitadas, reelaboradas.

Nesse sentido, acredito que não há proposta de ensino que se sustente na mera afirmação de pretender formar um profissional 'reflexivo, crítico e que tenha a perspectiva 
da integralidade do cuidado em saúde’: quais os significados destas expressões? Como a Psicologia tem estudado estes processos/atributos? Que ações efetivas no ensino de Psicologia representam a visibilidade destes termos? Como é (ou pode ser) organizado o processo ensino-aprendizagem no âmbito da Psicologia e suas articulações com os outros saberes para atingir o objetivo de formar um profissional engajado em um modelo de práticas de atenção a saúde que estejam orientadas pelos princípios do SUS? Como a Psicologia pode contribuir para uma aprendizagem interprofissional? Que temas/conteúdos/ estratégias parecem fazer sentido para e na construção de novos focos de assistência, ensino, pesquisa e articulação com a comunidade?

As respostas a estes questionamentos estão sendo construídas nas diversas e múltiplas experiências no campo da saúde, mas algumas dimensões parecem compor um quadro inicial bastante promissor: a prática profissional em saúde como eixo estruturante das situações de aprendizagem, o trabalho coletivo de professores e alunos, a participação do aluno nos processos de aprender e conhecer, as mediações docentes no sentido da reflexão, busca e análise das informações e saberes, o investimento em situações de extensão e pesquisa, inscrevendo as ações de aprendizagem e ensino no real, complexo e multideterminado mundo do trabalho em saúde.

Os sentidos e os sujeitos do ensino da Psicologia em saúde estão sendo decifrados e recriados, exigindo uma análise cuidadosa dos contornos político-sociais e dos projetos éticos que queremos estabelecer nas propostas de formação profissional em saúde.

A roda de discussão está aberta...

\section{REFERÊNCIAS}

ALMEIDA, M. Educação médica e saúde: possibilidades de mudança. Rio de Janeiro: Associação Brasileira de Educação Médica/ EDUEL, 1999.

BATISTA, N. et al. O enfoque problematizador na formação de profissionais de saúde. Revista de Saúde Pública, v.39, n.2, p. 147-161, 2005.

BATISTA, S. H. S. S. Formação. In: FAZENDA, I. (Org.). Interdisciplinaridade: um dicionário em construção. São Paulo: Cortez, 2001. 
BRASIL. CONSTITUIÇÃO DA REPÚBLICA FEDERATIVA DO BRASIL, 1988. Disponível em: www.planalto.gov.br/ccivil. Acesso em: 25 jul. 2005.

MINISTÉRIO DA SAÚDE. CONFERÊNCIA NACIONAL DE SAÚDE, 8,1986.

Disponível em www.conselho.saude.gov.br/conferencia. Acesso em: 25 jul. 2005.

MINISTÉRIO DA SAÚDE. LEI No 8080 DE 19 DE SETEMBRO DE 1990.

Disponível em: www.saude.inf.br/legisl/lei8080.htm Acesso em: 25 jul. 2005.

CANGULHEN, G. O normal e o patológico. 4. ed. Rio de Janeiro: Forense Universitária, 1995.

CECCIN, R. Inovação na preparação de profissionais de saúde e a novidade da graduação em saúde coletiva. Disponível em: www.opas.org.br/rh/admin/documentos/ceccinRB.pdf. Acesso em: 10 jul. 2005.

CONRADO, C.A. et al. A implantação das diretrizes curriculares nacionais de odontologia: a experiência de Maringá. São Paulo: Hucitec, 2004.

DELLAROZA, M. G.; VANNUCHI, M.O. (Org.). O currículo integrado do curso de enfermagem da Universidade Estadual de Londrina: do sonho à realidade. Londrina: Hucitec, 2005.

FEUERWERKER, L. Educação dos profissionais de saúde hoje: problemas, desafios, perspectivas, e as propostas do Ministério da Saúde. Revista da ABENO, São Paulo, v.3, n.1, p. 24-27, 2003.

FOUREZ, G. Interdisciplinarité et îlots de rationalité. Revue Candienne de l' enseignement des sciences, dês mathématiques et dês technologies, v 1, n.3, p. 341-348, juillet 2001,

KOMATSU, R. Aprendizagem baseada em problemas: sensibilizando o olhar para o idoso. Londrina/Rio de Janeiro/São Paulo: Rede Unida/ABEM/Sociedade de Geriatria e Gerontologia, 2003.

McNAIR, R. The case for education health care students in professionalism as the core content of interprofessional education. Medical Education, v. 39, n.5, p. 456-464, may 2005.

SANTOS, BOAVENTURA S. Pela mão de Alice: o social e o político na pósmodernidade. 3. ed. São Paulo: Cortez, 1997. 
